\title{
ASPECTS OF ORGANIZATIONAL COMMUNICATION INFLUENCING THE SUCCESS OF CHANGE
}

\author{
Orlando VOICA ${ }^{a *}$, Cristina VEITH ${ }^{b}$, Iyad ISBAITA $^{c}$ \\ ${ }^{a, b, c}$ Bucharest University of Economic Studies, Romania
}

\begin{abstract}
This paper aims to analyse some organizational routines that can influence the success of organizational change. Thus, we analyse several communicational elements that influence the implementation of a change, from the perspective of their interdependence. The data were collected through an online questionnaire and statistically evaluated. The quantitative analysis was based on the responses to questionnaire from 258 organizations in both public and private sectors.

We hypothesized that a successful change is reliant on some particular factors specific to the communication process. The analysis revealed that a personalized, demanding-focused communication is a determining factor for the success of any change. Materialized through the proper channel, this approach can determine the active and long-lasting involvement of team members in change implementation and goal-achievement processes.

Our actual research is limited in scale and scope, but its results are important for practitioners that intend to realize organizational changes, emphasizing the communication elements that they should focus on. Also, our study might be a support for future researches that focus on the impact that communication have on knowledge management processes during the organizational change initiatives.
\end{abstract}

KEYWORDS: change management, communication, COVID pandemic, Romanian organizations.

DOI: 10.24818/IMC/2021/05.03

\section{INTRODUCTION}

The current global situation is dominated by two important elements: the actions to implement a digital society and the Covid-19 pandemic. Changes in technological innovation have put pressure on all companies that actually feel the impact of the fourth industrial revolution. The changes sparked by the current industrial revolution have been accelerated by the Covid-19 pandemic.

Economic and social development has been influenced by several paradigm shifts, mostly due to innovations. They have had radical effects, being generally known as "industrial revolutions". A succession of industrial revolutions highlights the transition from mechanization (the first industrial revolution) to the use of electricity in all fields (the 2-nd industrial revolution) and automation (the 3-rd industrial revolution). The 4-th industrial revolution mainly refers to the substitution of manual operations by digital structures, automation and robotization of production processes, respectively the development of interaction and cooperation between man and artificial intelligence. Each of these industrial revolutions is characterized by major social, economic, technological and even political changes.

The current industrial revolution is undergoing under some critical factors, such as lack of skilled labour, global warming, increasing product variability, dynamism of the value chain, market volatilization and pressure to reduce costs (Lapidus, 2018). Product customization and reducing the

\footnotetext{
*Corresponding author. E-mail address: orlandovoica@yahoo.com
} 
production costs are phenomena that cannot work in parallel, because product customization causes additional costs. Currently, the life cycle of a product is shortened due to the dynamism of demand, and companies are forced to focus on innovation in the short term. Because of these elements the digitalization of processes is considered a potential solution and is currently on the agenda of many companies around the world.

In order to meet the challenges they face in the economic, social or technological field, organizations need to make changes to safeguard their survival and achieve the desired market share in Industry 4.0. However, this endeavour requires the manifestation of a specialized management, able to face the challenges.

\section{LITERATURE REVIEW AND HYPOTHESIS DEVELOPMENT}

The changes generated by technological innovations have created pressure on all companies, which are now feeling the impact of the fourth industrial revolution. Going beyond the limits reached in the Industrial Revolution 3.0 (Industry 3.0), which involved the automation of machines and production processes, the new Industrial Revolution 4.0 (Industry 4.0) encompasses digitizing and integrating data in the value chain, providing digital services operated by physical and virtual assets, transforming and integrating all internal operations and activities, building modern partnerships and optimizing the relationships with customers.

The concept "Industry 4.0" requires not only a deep understanding of the context but also a commitment to building viable industrial systems, with clear strategies for their development. Thus, European Union developed the Digital Europe Program aimed to invest a percentage of $15 \%$ of the multi-annual financial budget for the years 2021-2027 in the implementation of innovative digital technologies at economic and social level (Sabbati and Sapala, 2020).

Strategies based on the digitization process can lead to the efficiency of processes in companies, can reduce the volume of waste, can contribute to increasing the life cycles of products, etc. (BahnWalkowiak et al., 2020). Thus, supply chain structures in this new stage of development are characterized by flexible processes and high efficiency, elements that create cost savings while increasing customer benefits.

Dynamism is the key word in the 4.0 industry environment, a company being necessary to be very sensitive to the evolving needs of customers and the new type of competitors. In this context, the speed of change is accelerated, and the management of the enterprise is characterized by an intelligent approach to resources and production potential. Thus, from the point of view of human resources, Industry 4.0 need skills of different sizes to successfully manage business models and product portfolio, to access the market and potential customers, to improve processes and value chain systems, assuming the legal and cultural discrepancies resulting from globalization. Market demand for product diversification and customization are elements that normally create additional costs, and it is necessary to find an optimal balance between market pressures and the need to reduce production costs.

In addition to the pressure to adapt to the conditions imposed by the new 4.0 industrial revolution, the existence of the sanitary constraints imposed by COVID-19 gave a new impulse to the forces of change.

The COVID-19 crisis represents a new shock for the economic environment and for organizational life. The lack of direct interaction with customers and/or colleagues affects existing business models given that social isolation has profoundly influenced lifestyle and work.

In addition to the obvious negative effects at the economic level (reduction of economic activity, technical unemployment, inflation, etc.), the COVID 19 crisis also highlighted deficiencies of the education system, the labour market, etc. (Tecaru, 2021).

The solution for the current situation is to move from a reactive to a proactive management, to prevent and anticipate potential problems, respectively to achieve (and implement) viable plans for 
various scenarios (Bodea, 2020). These elements reflect the agility of companies, an element that determines the way a company behaves in case of a crisis (Serbancea, 2020).

Thus, the crisis created the opportunity to achieve synergies between the efforts to create a digital economy (specific to the Industrial Revolution 4.0) aiming for the development of more efficient financial and control systems, redesigning internal processes to increase the quality of services and products offered, respectively productivity, etc. All of these can only be achieved through processes of change.

Organizational change is the transition of the organization from the current status to a status that leads to an increase in its effectiveness (Gaffney, 2010). Musawir et al. (2017) consider that interventions aimed at changing the functioning of an organization must be done consciously, based on plans, so they consider planning as an important element for the success of change. McFillen et al. (2013) consider among the causes of change processes failure elements like the lack of preliminary analyses of the organizational situation and the existence of inadequate planning processes. However, planning for change must be done taking into account the perspective of employees, and Reis and Peña (2001) point out that change is sometimes initiated without understanding how the human element influences the success or failure of a project.

The success of change is assessed by each of the stakeholders, according to their needs and expectations. This is why communication is extremely important not only to reveal stakeholder expectations, but also to ensure a smooth implementation of organizational change, while managing the perception of individual benefits and satisfaction of change actors (Fabac, 2010).

The operational capabilities are accountable for achieving the organizational objectives. They are responsible for the activities that constitute the value chain of the organization, as well as of the supporting ones. In the event of a change, part of the operational capabilities of the organization becomes responsible for its efficient management and its "marketing". Thus, given that changes have (usually) SMART objectives, reflected in new ways of carrying out activities (operational routines), the actual change and adoption of new routines cannot be achieved without the conviction and involvement of all interested stakeholders. Thus, the internal communication capacity of the changing organization is extremely important.

Effective organizational communication is not a spontaneous and natural process. It involves managerial policies and strategies to formulate both the objectives of reception and of the transmission of messages, in order to generate the desired results. An organized communication must be goal-oriented, multidirectional, instrumental, adaptive, and flexible.

Internal communication refers to the exchange of messages that takes place within the organization, both vertically and horizontally. Communication is formal when messages are transmitted on predetermined channels grounded on a formal system of responsibilities that respects the hierarchical structure of the organization. Formal channels are designed and managed to allow the transfer of information between hierarchical levels (vertically) and departments (horizontally), communication generally taking place in three main directions: top-down, bottom-up and horizontally. When information flows through channels that do not fall within the scope of subordinate relations, it is informal communication.

The success or failure of an organizational change endeavour is determined by the effectiveness of the implementation of planned processes, which are usually affected by situational factors. Rosenbaum et al. (2018) recognize the importance of the interactions between management and employees/customers during the change process and consider that organizational responses to situational stimuli involve a wide range of organizational attributes.

Accordingly, the implementation of changes requires effective communication flows, which ensure the relevant information for all stakeholders. In this sense, at the organizational level is necessary for change leader to distinguish between information (which is exclusively related to the unidirectional transfer of content), and communication - a term that refers to a system of interactive, interpersonal relationships aimed to change the behaviour of the interlocutor. These elements are 
specific to the formal or informal processes of persuasion regarding the need for change and its urgency, carried out by managers during the change processes.

Through these processes, individuals who have to implement the change receive the proper information, necessary for each one to accept the individual/global benefits that can be obtained. This alignment of organizational and individual objectives is an element without which the success of a change approach cannot be ensured (Castillo et al., 2018). This idea is consistent with Branson (2008) who argues that the foundation of successful organizational change is the alignment of individual values with those of the organization. Thus, Rogiesta et al. (2018) highlights the fact that in the change processes it is important that the information should be provided at the right time and be useful to the people who receive them. Thus, the communication processes aim to provide relevant information about the current and future status of the changes.

An element often associated with change implementation failure is the resistance to change. It requires efforts of those involved overcoming its effects (Carnall, 2007). Resistance to change arises in most cases from a position of misunderstanding and involvement (Lewis, 2011). Acceptance is liable to the personal characteristics of individuals and can be influenced by persuasive communication methods (Rogers, 2003). In this context Shikhar et al. (2009) reveal that the existence of detailed information supports the individual's identification of the benefits of change, benefits that are appreciated by him.

In our research we formulated three hypotheses, which are to be verified using quantitative analysis. H1: the type of communication, the content and the precision of the transmission of the message together with the involvement of the members of the organization in the direction of implementing the organizational objectives are important elements that will influence the change results.

$\mathrm{H} 2$ : the success of change is influenced by the flow of communication (bottom, top-down and degree of formalization).

H3: personalized approach of each target audience influences of implementing change efforts.

\section{RESEACH METHODOLOGY}

The paper aims to analyse and identify the role that some specific communication routines have in the implementation of organizational change. The routines were identified in the literature following the analysis of theoretical concepts related to change management.

In order to identify the most appropriate method of analysis we considered the use of qualitative or quantitative method. As long as the literature does not indicate a specific method for analysing and collecting data, we focused mainly on the topic and its complexity. Change can be influenced by a multitude of factors, which must be grouped and organized to permit viable conclusions to be drawn.

Thus, after analysing the concepts and crystallizing the items, we created a questionnaire based on an ordinal scale that gives the possibility of hierarchical measurement and allows the establishment of an orderly relationship between data. Thus, the respondents chosed on an ordinal Likert scale from 1 to 4 the hierarchical level that they considered the most appropriate for each of the analysed factors. The questionnaire also included 5 classification factors, such as type of organization, age group of respondents, level of training, gender, hierarchical position in the organization.

The questionnaire was exposed to the analysis of a number of 5 professionals in the field of management, with experience in change management. The final version of the questionnaire, revised according to the comments, was posted online. The questionnaire was popularized online to practitioners in organizations that have implemented a change in the last two years prior to the questionnaire fulfilment.

We received 258 answers from public and private organizations in which changes have been implemented in the last two years prior to the completion of the questionnaire as follows: 70 $(27.13 \%)$ responses from public organizations and 188 responses $(72.87 \%)$ from private 
organizations. Both women and men answered our questionnaire almost equally. A number of 202 people $(78.29 \%)$ were respondents between 30 and 50 years old and 242 answers $(93.80 \%)$ came from people with a high level of training, i.e., who graduated from a university at master's level. The respondents were responsible for implementing change, 224 people (86.82\%) being top or middle managers.

After performing the descriptive statistical analysis, we proceeded to evaluate the main communicational components that influence the success of the change. The large number of communicational factors involved in change made us chooses the factor analysis. The grouping of the different factors in defining components helped us to understand the main communicational aspects through which we can influence the achievement of the change objectives of each organization.

In the factor analysis, 11 factors were taken into account, which were grouped into three components whose variance influences change.

\section{RESULTS}

The first step was to verify the correlation between the 11 factors considered in the factor analysis. All variables met both the correlation condition and the normal or near-normal distribution condition.

Factor analysis was applied for the 258 responses received. In order to ensure the validity of the obtained results, we also applied the KMO and Bartlett's Test, which we present in table 1.

Table 1. KMO and Bartlett's Test

\begin{tabular}{|c|c|c|}
\hline \multicolumn{2}{|c|}{$\begin{array}{c}\text { Kaiser-Meyer-Olkin Measure of Sampling } \\
\text { Adequacy. }\end{array}$} &, 862 \\
\hline \multirow{2}{*}{$\begin{array}{c}\text { Bartlett's Test of } \\
\text { Sphericity }\end{array}$} & $\begin{array}{c}\text { Approx. Chi- } \\
\text { Square }\end{array}$ & 941,700 \\
\cline { 2 - 3 } & df & 55 \\
\cline { 2 - 3 } & Sig. &, 000 \\
\hline
\end{tabular}

Source: SPSS 21 result for KMO and Bartlett's Test

The value of 0.862 of the Kaiser-Meyer-Olkin indicator shows us that the number of cases considered is very good for our analysis. All three elements of Bartlett's Test of Sphericity have good values.

In table 2 we present the results of Factor Analysis/Principal Component Analysis for 11 components of communicational practices. Three components were extracted for which the Eigenvalues is greater than 1,000. The analysis of variance indicates that those three main components cumulatively explain almost $61 \%$ of the total variance.

The three components extracted explain almost $61 \%$ of the variance of the analyzed factors. This value is sufficient to determine the elements that an organization must focus on when planning to implement a change.

In the graphical representation provided by Figure 1 we can also see the differences in the percent of variance explained by each component extracted. While the first component explains over 39\% of the total variance, the next two components explain only approximately $12 \%$ and $10 \%$.

Starting from component four downwards, the slope between components becomes smoother, but below the eigenvalue of 1 . 
Table 2. Total Variance Explained for low results of the change

\begin{tabular}{|c|c|c|c|c|c|c|c|}
\hline \multirow[b]{2}{*}{ Component } & \multicolumn{3}{|c|}{ Initial Eigenvalues } & \multicolumn{3}{|c|}{$\begin{array}{c}\text { Extraction Sums of Squared } \\
\text { Loadings }\end{array}$} & \multirow{2}{*}{$\begin{array}{c}\text { Rotation } \\
\text { Sums of } \\
\text { Squared } \\
\text { Loadings } \\
\text { Total } \\
\end{array}$} \\
\hline & Total & $\begin{array}{c}\% \text { of } \\
\text { Variance }\end{array}$ & $\begin{array}{l}\text { Cumula- } \\
\text { tive } \%\end{array}$ & Total & $\begin{array}{c}\% \text { of } \\
\text { Variance }\end{array}$ & $\begin{array}{c}\text { Cumula- } \\
\text { tive } \%\end{array}$ & \\
\hline 1 & 4,296 & 39,054 & 39,054 & 4,296 & 39,054 & 39,054 & 3,822 \\
\hline 2 & 1,311 & 11,921 & 50,975 & 1,311 & 11,921 & 50,975 & 1,258 \\
\hline 3 & 1,099 & 9,989 & 60,964 & 1,099 & 9,989 & 60,964 & 3,043 \\
\hline 4 & ,894 & 8,128 & 69,092 & & & & \\
\hline 5 & ,805 & 7,321 & 76,413 & & & & \\
\hline 6 & ,655 & 5,951 & 82,364 & & & & \\
\hline 7 & ,500 & 4,543 & 86,907 & & & & \\
\hline 8 & ,416 & 3,781 & 90,687 & & & & \\
\hline 9 & ,369 & 3,356 & 94,043 & & & & \\
\hline 10 & ,336 & 3,058 & 97,101 & & & & \\
\hline 11 & ,319 & 2,899 & 100,000 & & & & \\
\hline
\end{tabular}

Extraction Method: Principal Component Analysis.

a. When components are correlated, sums of squared loadings cannot be added to obtain a total variance.

Source: SPSS 21 result for Factor Analysis/Principal Component Analysis

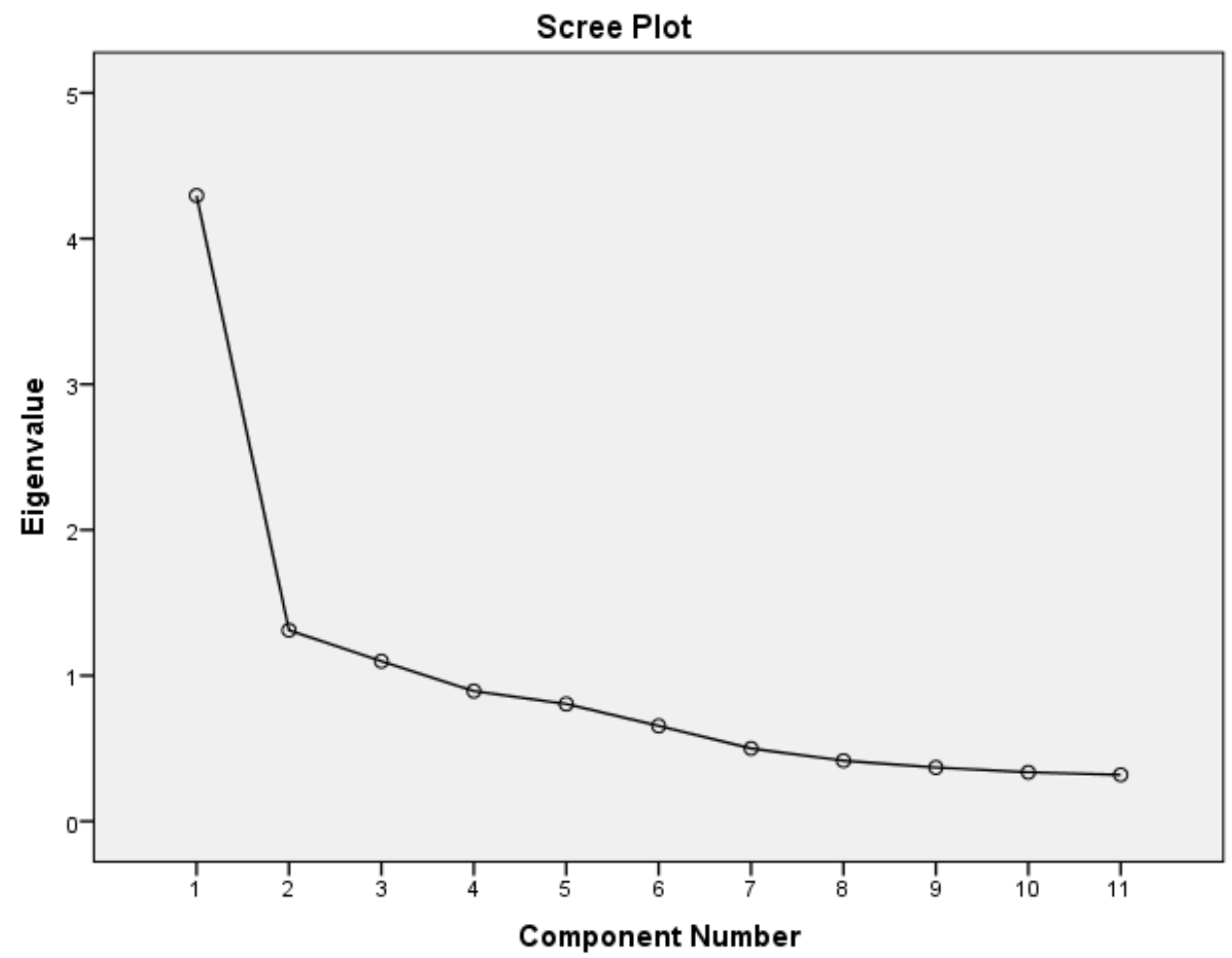

Figure 1. Principal Component Analysis spss plot result for change management Source: SPSS 21 result 
In the next stage we analysed the correlation matrix of the three chosen components, in order to establish the most appropriate type of rotation that would facilitate an easier interpretation of the obtained results.

Thus, as we observed in table 3, there is a correlation higher than 0.400 present between components 1 and 3, therefore, according to the rules of factor analysis, we choose to perform the analysis using the "Oblimin" type rotation with Kaiser Normalization.

Table 3. Component Correlation Matrix

\begin{tabular}{|c|c|c|c|}
\hline Component & 1 & 2 & 3 \\
\hline 1 & 1,000 &,- 027 &, 467 \\
\hline 2 &,- 027 & 1,000 &, 059 \\
\hline 3 &, 467 &, 059 & 1,000 \\
\hline
\end{tabular}

Extraction Method: Principal Component Analysis.

Rotation Method: Oblimin with Kaiser Normalization. Source: SPSS 21 result

Table 4 presents the pattern matrix that reveals the factors that make up each of the three components.

\section{DISCUSSION}

The first and most important component is revealed by five factors, in the order of their importance, namely: The messages ask for the participation of employees in achieving the goal, Communication generates employee involvement for the goals achieved, Messages are sent in a timely manner right on time, Content of the messages are the organizational realities and Assertiveness of communication. We call the first component Demanding Communication.

The second component refers to the degree of organizational formalization of the communication flow. It is composed of the following three factors: Communication Level of formalization, Communication Top-down flow and Communication Bottom-up flow. We call this component Communication Flow.

The last component that results from our analysis is the Personalized Communication. This component reveals the importance to the individualization of messages according to the target group, with the presentation of individual benefits and the addition of emotions in the content of the message. For the recipients of the message, the inclusion of an emotional content is the most important factor within this component. This illustrates once again that people need emotional messages that are effective in revealing both individual and general benefit. However, even if from the manager's perspective it is hard to address everyone individually, in a change endeavor the messages must be customized according to each target group. 
Table 4. Pattern matrix

\begin{tabular}{|l|c|c|c|}
\hline & \multicolumn{2}{|c|}{ Component } \\
\cline { 2 - 4 } & 1 & 2 & 3 \\
\hline $\begin{array}{l}\text { The messages ask for the participation of employees } \\
\text { in achieving the goal }\end{array}$ &, 863 & & \\
\hline $\begin{array}{l}\text { Communication generates employee involvement for } \\
\text { the goals achieved }\end{array}$ &, 844 & & \\
\hline Messages are sent in a timely manner right on time &, 825 & & \\
\hline Content of the messages: the organizational realities &, 651 & & \\
\hline Assertiveness of communication &, 638 & & \\
\hline Communication Level of formalization & &, 768 & \\
\hline Communication Top-down flow & &,- 758 & \\
\hline The messages have emotional content & & &, 897 \\
\hline $\begin{array}{l}\text { The messages are personalized highlighting the } \\
\text { individual benefit }\end{array}$ & & &, 744 \\
\hline Each target audience is approached differently & & &, 703 \\
\hline Communication Bottom-up flow & &, 634 & \\
\hline
\end{tabular}

Extraction Method: Principal Component Analysis.

Rotation Method: Oblimin with Kaiser Normalization.

a. Rotation converged in 6 iterations.

Source: SPSS 21 result for Factor Analysis/Principal Component Analysis

Based on the results we can say that hypothesis H1 (type of communication, content and accuracy of messages along with the involvement of organization members in the direction of implementing organizational objectives will influence the results obtained by the chosen change) is confirmed.

More than we expected at the beginning of the analysis, it should be emphasized that component 1 , not only generally influences the change, but also has a major contribution to achieving the desired results by the organization.

Hypothesis $\mathrm{H} 2$ is related to the communication flow. Our result shows that the ways of communication (bottom, top-down and degree of formalization) influence the success of the change, but explain only $12 \%$ of the total variance.

Last, but not least, our research confirms Hypothesis H3, revealing that a personalized approach of each target audience influences the implementing change efforts. However, factors mentioned of Component 3 explain only approximately $10 \%$ of the total variance.

\section{CONCLUSIONS}

In the current context, when global current situation is dominated by the actions to implement a digital society and the Covid-19 pandemic, change has become part of everyday life, therefor it becomes more important for each organization to understand the factors that can influence the change processes.

This paper aims to analyse some communicational routines that can influence the success of an organizational change. Thus, in this paper we analyse several communicational factors that influence the implementation of a change, from the perspective of their interdependence. The 11 factors analysed in our paper belong to an extended series of factors proposed to evaluate the organizational change environment and processes. The data were collected through a questionnaire and statistically evaluated with the SPSS 21 program, using factor analysis. The quantitative analysis was based on the responses to an online questionnaire from 258 organizations in both the public and private sectors. 
The analysis revealed that a demanding communication is important in a change endeavor. The content of the message should ask for the individual involvement in achieving the organizational results. The messages should be sent in a timely manner/right on time, reflecting the organizational realities. Last, but not least, the communication should be assertive.

Communication flow for exchanging ideas and information that are relevant for change implementation and goal-achievement is also extremely important. Top-down and bottom-up flows of information have their role and a trade-off between them should be secured by the change leaders considering the fact that that both employees and managers feel better in modern organizations in the role of colleague than in that of executor or authoritarian superior. However, each member of the organization must develop their communication skills in order to deliver information related to change status or to integrate himself in the communication channels that exist within organization, information that are necessary to achieve both personal and organizational the desired results.

Last, but not least, a personalized approach of each target audience influences the change implementation efforts. Even if, usually, some practitioners do not give the proper attention to the particularization of the message for each target group, we conclude that addition of emotional elements in the content of the message influence the individuals' desire to involve themselves and to participate to the change implementation. However, a presentation of individual benefits (WIIFM) could boost employees' desire to participate and add value in a change attempt. This approach might be difficult to be realized at the individual level, but in a change endeavour the messages must be customized according to each target group.

Our actual research is limited in scale and scope, but its results are important for practitioners that intend to realize organizational changes sparked by the efforts to make transition to a digital society and in the context of the Covid 19 pandemic, emphasizing the communication elements that they should focus on.

Our study might be a support for future researches that focus on the impact that communication have on knowledge management processes during the organizational change initiatives.

\section{ACKNOWLEDGMENT}

The authors are students at the Bucharest University of Economic Studies. Many thanks to all our respondents, to the teachers who guided us permanently.

\section{REFERENCES}

Bahn-Walkowiak, B., Magrini, C., Berg, H., Gözet, B., O'Brien, M., Arjomandi, T. \& Bleischwitz, R. (2021). Eco-innovation and digitalisation: case studies, environmental and policy lessons from EU member states for the EU green deal and the circular economy: EIO biennial report 2020. Brussel: European Commission. Retrieved from https://nbnresolving.org/urn:nbn:de:bsz:wup4-opus-77538

Bodea, D. (2020, April 28). Cum se face managementul crizei în vremea COVID-19. Retrieved from forbes.ro: https://www.forbes.ro/articles/managementul-crizei-vremea-covid-19-162342

Branson, C. (2008). Achieving organisational change through values alignment. Journal of Educational Administration, 46(3), 376-395. Retrieved from https://doi.org/10.1108/09578230810869293

Carnall, C. (2007). Managing Change in Organizations. Pearson Education.

Castillo, C. F. (2018). The six emotional stages of organizational change. Journal of Organizational Change Management, 31(3), 468-493. doi:https://doi.org/10.1108/JOCM-05-2016-0084.

Fabac, R. (2010). Complexity In Organizations And Environment - Adaptive Changes And Adaptive Decision-Making. Interdisciplinary Description Of Complex Systems, 8(1), 34-48. 
Gaffney, S. (2010). Dynamics of Organisational Change - the Belfast model. Gestalt Journal of Australia and New Zealand, 7(1), 75-88.

Gibson, M. (2020, December 15). Change management trends to watch in 2021. Retrieved from logic2020.com: https://www.logic2020.com/insight/change-management-trends-2021

Lapidus, L. V. (2018). Economia digitală: managementul afacerilor electronice și electronice. INFRA-M, 381-382. doi:9785160136400

Lewis, L. (2011). Organizational Change: Creating Change through Strategic Communication (Vol. 4). West Sussex: John Wiley \& Sons.

McFillen, J. M., O’Neil, D. A., Balzer, W. K. \& Varney, G. H. (2013). Organizational diagnosis: an evidence-based approach. Journal of Change Management, 13(2), 223-246.

Musawir, A., Serra, C. E., Zwikael, O. \& Ali, I. (2017). Project governance, benefit management, and project success: Towards a framework for supporting organizational strategy implementation. International Journal of Project Management, 35, 1658-1672.

Reis, D. \& Peña, L. (2001). Reengineering the motivation to work. Management Decision, 39(8), 666-675. doi:https://doi.org/10.1108/EUM0000000005929

Rogers, E. (2003). Diffusion of innovations (5 ed.). New York: Free Press.

Rogiest, S., Segers, J. \& van Witteloostuijn, A. (n.d.). Matchmaking in organizational change: Does every employee value participatory leadership? An empirical study. Scandinavian Journal of Management, 34, 1-8.

Rosenbaum, D. M. (2018). Planned organisational change management: Forward to the past? An exploratory literature review. Journal of Organizational Change Management, 31(2), 286-303. doi:https://doi.org/10.1108/JOCM-06-2015-00

Sabbati, G. \& Sapala, M. (2020, 01 24). The 2021-2027 Multiannual Financial Framework in figures. (E. U. Tank, Ed.) Retrieved from https://www.europarl.europa.eu/ thinktank/en/document.html?reference=EPRS_BRI(2020)646131

Sarin S., Colarelli O'Connor G. (2009). First among Equals: The Effect of Team Leader Characteristics on the Internal Dynamics of Cross-Functional Product Development Teams. Journal of Product Innovation Management, 26, 188-205. doi:https://doi.org/10.1111/j.15405885.2009.00345.x

Serbancea, M. (2020, 05 19). Retrieved from https://blog.pwc.ro/2020/05/19/cum-se-pot-adaptacompaniile-la-schimbare-chiar-si-in-criza-tehnologia-este-esentiala-dar-planificarea-sitalentele-fac-diferenta/ Tecaru, A.-D. (2021, March 02). Managementul schimbării în vremuri

Serbancea, M. (2020, May 19). Cum se pot adapta companiile la schimbare, chiar și în criză: Tehnologia este esențială, dar planificarea și talentele fac diferența. Retrieved from pwc.ro: https://blog.pwc.ro/2020/05/19/cum-se-pot-adapta-companiile-la-schimbare-chiar-si-in-crizatehnologia-este-esentiala-dar-planificarea-si-talentele-fac-diferenta/

Tecaru, A.-D. (2021, March 02). Managementul schimbării în vremuri de COVID. Retrieved from jobshub.ro: http://blog.jobshub.ro/Post/2021/3/2/managementul-schimbarii-in-vremuri-decovid. 